Spectral and Chemical Characterisation of Organic Compounds: $A$ Laboratory Handbook. By W. J. Criddle and G. P. Ellis. Pp. viii +103. (Wiley: London and New York, February 1976.) £4.60; $\$ 10.15$.

THE avowed purpose of this book is to bring together, in one small volume, the information a student is likely to need in the laboratory to enable him to establish the identity of organic compounds whose structures are unknown to him. The chemical part of the book is of a familiar type embracing short chapters on preliminary tests, separation of mixtures, the preparation of derivatives, followed by 50 pages of tables of melting points of these derivatives. There is also a short chapter on pharmaceutical compounds.

The book's main claim resides in the second chapter-chemical and spectroscopic characterisation of functional groups-and it must be said that there is not really sufficient emphasis on spectroscopic data; there is, for example, no mention of mass spectra at all. Students will thus need to buy a book on the interpretation of spectra; they are unlikely to buy this book as well just for its melting point data-which they can obtain from the larger reference books in the laboratory in any case.

Peter Sykes

Mosquito Ecology: Field Sampling Methods. By M. W. Service. Pp. xii +583. (Applied Science : London, 1976.) $£ 30$.

Almost as many ways have been devised of collecting mosquitoes as there have been field workers. In his book Dr Service has reviewed some hundreds of these methods, and managed to do so in a readable and informative fashion. Many of the traps and sampling devices were designed simply for the collection of large numbers of individuals, but others provide data which contribute towards an understanding of mosquito ecology. The latter are rightly given more emphasis, with accompanying descriptions of methods of analysing the data.

The early chapters deal with the sampling of eggs and larvae, but the bulk of the book is concerned with adults. Descriptions are given of traps for adults as they emerge from their larval habitats and for sampling from resting sites. Attractant and nonattractant traps are most fully covered, and a short chapter is included on the use of experimental huts for evaluating insecticides. The descriptions are supplemented with clear line drawings.

The sections dealing with population size estimation-for example, by mark-release-recapture techniques or sequential sampling-and the chapter on estimating mortality in immatures and adults are perhaps too condensed, but there is compensation in the full bibliography.

The book was written for the field worker; it should meet his needs admirably.

W. W. Macdonald

\section{Books brief}

The Brown Rat. By Graham Twigg. Pp. $150+8$ plates. (David and Charles: Newton Abbot, London, North Pomfret, Vermont and Vancouver; January 1976.) £4.95.

THIS chatty account of Rattus norvegicus is evidently addressed primarily to laymen. It has, however, a useful, if patchy, bibliography, and some good information on the brown rat as a food pest and vector of disease. Topics include populations and other aspects of rat ecology, reproduction and-too briefly-control. Examples are mainly from Britain and North America. Among diseases, special attention is given to plague and leptospirosis. The account of the biology of rats does not do justice to their very important exploratory behaviour. The author is also quite at sea on their social conduct. There are plenty of illustrations - some goodand an index. The book may serve to introduce readers to aspects of economic zoology and public health that ought to be more widely known.

S. A. Barnett

Membranes: A Series of Advances. Vol. 3, Lipid Bilayers and Biological Membranes: Dynamic Properties. Edited by George Eisenman. Pp. xiv +538. (Dekker: New York and Basel, 1975.) \$42.50.

THE proliferation of books has rarely little to commend it, but Volume 3 of Eisenman's Membranes is quite definitely an exception. It brings together in one volume a group of first-class papers by acknowledged experts in the field of ion permeation and selectivity in biological systems which will be of great value to everyone--student, teacher and research worker-interested in this field.

Chapters on the Structure and Dynamic Properties of Ion-Specific Antibiotics (Grell, Funck and Eggers), The Kinetics of Carrier-Mediated Ion Permeation in Lipid Bilayers and its Theoretical Interpretation (Laprade, Ciani, Eisenman and Szabo) and The Action of Uncouplers on Lipid Bilayer Membranes (Neumcke and Bamberg) are set alongside chapters on Ionic Selectivity of $\mathrm{Na}$ and $\mathrm{K}$ Channels of Nerve Membranes (Hille), Potassium Pores of Nerve and Muscle Membranes (Armstrong), CaDependent Action Potential (Hagiwara) and Cation Permeation Mechanisms and Cation Selectivity in Tight Junctions of Gallbladder Epithelium (Moreno and Diamond).

This book is well produced and readable and should remain a valuable reference work for a number of years.

P. F, Baker

Laser Doppler Measurements. By B. M. Watrasiewicz and M. J. Rudd. Pp. viii +160 . (Butterworths: London and Boston, Massachusetts, 1976.) £6.90.

THIS is an attractive little volume in which the principles and the practice of laser anemometry -the measurement of the velocity of winds and related phenomena-are outlined in stages of progressive complexity. Out of the wealth of dynamic phenomena which can be investigated by study of the light scattered from particles in motion, the authors have chosen to concentrate on the single topic of laminar and turbulent fluid flow. They discuss in succession historical developments, principles of the laser and scattered light detection, simplified theories of laser anemometers, as well as more detailed aspects; problems related to signal processing in the frequency and time domains, measurement of turbulence parameters and applications in wind tunnels and in the atmosphere. Being myself a non-specialist in anemometry but deeply interested in other aspects of laser light scattering, $I$ found the description and analysis rewarding. I believe the book to be equally useful to novices of this discipline. It would seem, however, that the specialist working in the field is well acquainted with the bulk of the material.

H. Eisenberg 